\title{
Correspondence
}

Because of heavy pressure on our space, correspondents are asked to keep their letters short.

\section{The Heart and Digitalis}

SiR, - My friends Drs. Harold Cookson (July 27, p. 249) and Bruce Williamson (August 17, p. 442) have both been kindly in their remarks while questioning my statement in the Withering Lectures (July 13, p. 73) that thyrotoxic heart failure may be susceptible to improvement on digitalis.

I cannot, of course, compete with Dr. Cookson in numbers of patients studied, nor can I say how often digitalis can be used successfully, but direct bedside observation of a few cases has shown results such as those in the accompanying chart of a patient with thyrotoxic cardiac failure. Giving digitalis alone for 14 days led to a rapid decrease of

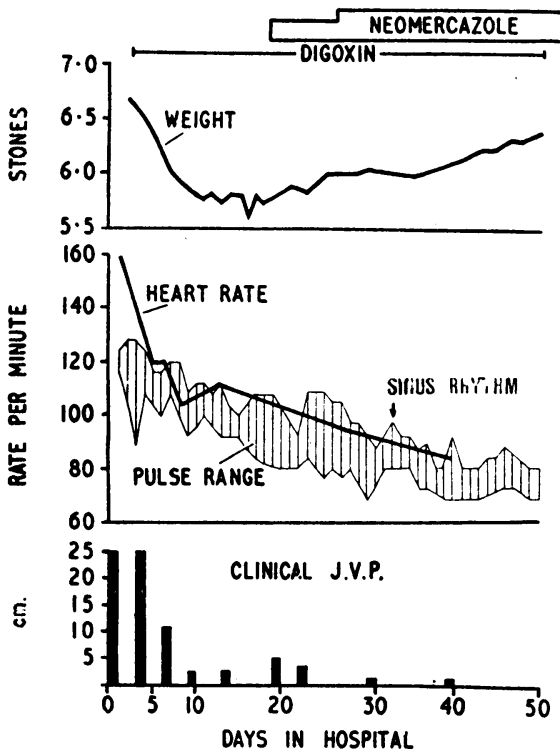

jugular venous pressure, reduction of ventricular rate, disappearance of tricuspid incompetence, and loss of weight from disappearing oedema. After this stage neomercazole brought the thyrotoxicosis under control with gain of weight due to nutritional improvement and further amelioration of the heart condition with disappearance of fibrillation at the end of a month.

I am sure one of the reasons for the lack of faith in digitalis in thyrotoxic fibrillation is that very often the ventricular rate is exceedingly rapid (e.g. 190 per minute) and digitalis slowing, improving the rate to 130 per minute, may not be regarded as satisfactory. Nevertheless, this manifestation of digitalis action can be accompanied by a quite dramatic change for the better. Divergence of opinion among experienced people, however, is clearly an indication of the need for further research. Thyrotoxic heart failure involves a great deal more than a mere metabolic overloading, and I hope that its detailed mechanism will be more clearly defined in the future.

I do not regard the oral use of digoxin as dangerous when failure supervenes even in acute infarction, and I have consistently used it for many years. Massive intravenous dosage should be avoided, however, for the reasons suggested by Dr. N. P. Saheta (August 31, p. 561). The paroxysmal dysrhythmias are a separate and special problem.

With regard to the contribution of slowing of the heart, the physiological evidence presented is against any vagus influence causing improved cardiac contraction, and is rather in favour of the opposite-certainly the experiments of Sarnoff quoted ruled out any influence on contractility of changing coronary flow. Striking digitalis benefits are often seen clinically in ischaemic heart disease where any increase in coronary flow would be extremely unlikely from the nature of the pathological process. In any case these arguments are somewhat redundant in face of the now massive evidence both from human and animal observation that digitalis improves, by a direct effect, the contractile force of the failing myocardium. The final answer on the mechanism of this action will almost certainly emerge from the detailed analysis of muscular contraction and especially the role of ionic interchange by modern biochemical and physiological techniques. We should at least prepare our minds for the reception of new ideas on the theoretical bases of our work.I am, etc.,

$$
\begin{aligned}
& \text { Postgraduate Medical School. } \\
& \text { London W.12. }
\end{aligned}
$$

\section{Present State of Medicine}

SIR,-Your diagnosis of the malaise which afflicts British general practice (August 24, p. 454) impressed me by its thoroughness but not by its cogency. It reminded me of the diagnostic appraisal of an over-learned medical student. A wide field was covered, many possibilities were mentioned, initials and abbreviations were broadcast, but at the end one was left bewildered and none the wiser. Sir, I am tempted to say to you as I might to that final-year student. " Come, let's have it in a nutshell-one word or one sentence, please." If one could imagine someone of your exalted position thus put on such a spot, there could only be one answer: "The capitation system."

To impartial observers in this country and abroad it seems so obvious. Anyone who read Sir Theodore Fox's account' of his voyage of exploration amongst the doctors of Australia and New Zealand must have been impressed by his description of the enthusiasm of their G.P.s, their knowledge, and the way their patients relied on them for so much which in this country is done by hospitals. My exhousemen who have emigrated tell me the same; and my friends in general practice in the United States and Canada give a similar impression of satisfaction with their way of life. They have fewer patients, they do less trivial and more responsible work, they are respected, and they earn more. They don't have a capitation system.

You bewail the fact that the general practitioner is cut off from the work of the hospitals in this country, and you give as one of the reasons that the consultant is now less (financially ?) dependent on his G.P. colleagues. The insinuation is. an unworthy one, but the fact is indisputable. I for one am glad of this. independence. Twenty years ago I might have been afraid to write a letter like this. to you. Now I can say sincerely that in my opinion G.P. politicians must blame themselves for the present state of affairs, because they sold out for the security of the capitation fee. Secondly, having accepted it, many have failed to accept the clinical responsibility which is the life-blood of happy medical practice. How many general practitioners use and interpret the pathological and radiological services available to them for many years in most cities? How many give themselves the satisfaction of sewing up a wound or removing a sebaceous cyst? How many try simple psychotherapy rather than peddling pills? I can't give an accurate answer and 1 doubt whether anyone can, but the impression one gets as a consultant is. that only about a third of the city doctors do these things, whereas nearly all country and country-town doctors accept such responsibilities and enjoy their life. No doubt they feel poor but happy.

The picture with regard to the postgraduate services and hospital meetings to which G.P.s are invited has the same general cast but less of a rural-urban bias. A loyal band of about a quarter of the G.P.s in an area turn up at nearly all the postgraduate functions-the same $25 \%$ nearly every time. They look tired, but keen and happy. The other $75 \%$ may be too busy writing angry letters to the B.MJ. about remuneration. But who can blame a G.P. for not doing his own minor surgery or his own psychotherapy, for not taking blood specimens to the laboratory, for not having a receptionist and an appointments system, when these things cost the money and time which he feels he can ill afford, and when the State, his employer, rewards him with nothing for his effort? This is the evil of the capitation system, and 15 years of experience in Britain show that the tremendous sacrifice and sense of dedication of so many G.P.s have not been enough to conquer that evil.

So much for my firm diagnosis, but like all physicians I find the treatment 